\title{
Life cycle thinking in small and medium enterprises: the results of research on the implementation of life cycle tools in Polish SMEs-part 1: background and framework
}

\author{
Przemyslaw Kurczewski
}

Received: 12 August 2013 / Accepted: 20 November 2013 / Published online: 11 December 2013

(C) The Author(s) 2013. This article is published with open access at Springerlink.com

\begin{abstract}
Purpose This article is the first of a series of articles presenting the results of research on the implementation of life cycle management tools in small- and medium-sized companies in Poland. This work is part of a project financed by the Polish Agency for Enterprise Development (PAED) which began in February 2011. It was carried out by the Wielkopolska Quality Institute - a business environment institution associated with the Polish Centre for Life Cycle Assessment (PCLCA). The main practical objective of the project was to support small and medium enterprises (SMEs) in their business development, e.g. by expanding their horizons beyond the sphere of their operation and identifying new areas for improvement and promotion of the products and services on offer. These publications are a voice in the discussion on the opportunities and pertinence of implementing life cycle thinking (LCT) in small- and medium-sized enterprises and an attempt to identify potential barriers arising from specific characteristics of SMEs which could hinder or even prevent the effective implementation of life cycle techniques. Part 1 presents the situation of SMEs in Poland, general objectives of the project and organisation of the survey process.

Methods It was decided to carry out research on the effectiveness of the implementation of LCA and life cycle costing (LCC) in organisations that had received financial support for the implementation of life cycle techniques. Financial constraints, which might potentially be a reason for limited interest in LC techniques among SMEs in Poland, were taken into account. Thus, financial support provided an opportunity
\end{abstract}

Responsible editor: Gian Luca Baldo

Any academic institution based in Poland

P. Kurczewski $(\bowtie)$

Faculty of Machines and Transport, Poznań University of

Technology, Piotrowo 3, 60-965 Poznań, Poland

e-mail: przemyslaw.kurczewski@put.poznan.pl for the project to obtain information from a wide range of companies, not only from those companies that were particularly aware of the benefits of LC techniques or had a very good financial situation. Research based on the method of individual in-depth interviews was preceded by an analysis of literature showing the status of SMEs in Poland. Given the results, the project objectives were formulated and the ways of conducting the research were defined.

Results and discussion The comparison of Polish SMEs with the same category of companies in the EU shows some similarities, such as the percentage of companies engaged in various businesses. The differences are expressed primarily in the financial potential, which in the case of Polish SMEs, is significantly smaller than the average in the EU. In the SME sector, there are less than half as many small businesses in Poland than in the EU. There are, however, many more microbusinesses in Poland. An evaluation of the prevalence of LCA and LCC techniques indicates that they are used by just $3 \%$ of Polish SMEs, which is a very small proportion compared to the more than $50 \%$ of SMEs taking any environmental measures. Information collected on specific details of Polish SMEs was used to identify the target group and develop a survey questionnaire which aimed to audit, among other things, the approach to environmental and economic analyses in the past and the approach to the LCA and/or LCC analyses that were implemented from the point of view of difficulties in their implementation and potential use of the results.

Conclusions Part 1 of the series of articles demonstrates a marginal-scale dissemination of life cycle management techniques among Polish SMEs. Companies definitely prefer to introduce relatively simple solutions that do not require specialised knowledge or unnecessary costs, e.g. they introduce energy-saving bulbs and waste segregation. Only a small percentage of companies implement more complex activities, and most commonly, these are medium-sized companies with greater financial and human capital. So what should be done 
to make SMEs use life cycle techniques more frequently? Is it appropriate to make changes in the methodology and life cycle techniques as such, or should, rather, the incentive for SMEs to use LCT come from outside as a requirement of public institutions or suppliers in a supply chain? Answers to these questions are provided in the research conclusions presented in parts 2 and 3 of the series of articles.

Keywords Implementation $\cdot$ LCA $\cdot$ LCC $\cdot$ LC thinking · SMEs

\section{Introduction}

Life cycle thinking (LCT) is becoming an increasingly common practice among enterprises in different areas of business. Guidelines included in LCT implementation methods known from the literature indicate tools (Jensen and Remmen 2006) that help develop a comprehensive analysis of environmental impacts, economic costs and social consequences incurred throughout the life cycle of products. Although methods such as life cycle assessment (LCA), life cycle costing (LCC) and social LCA (SLCA) are well known from the literature, they are generally still much more popular among large-sized enterprises (Baumann 2000; Frankl and Rubik 2000; Rex and Bauamnn 2004), for example, in the automotive (Agarski et al. 2012; Schmidt et al. 2004; Schmidt and Taylor 2006) or metal industries (Bieda 2012a, b). Their prevalence also varies depending on the country, size of business, type of business and the industry in which companies operate (Baumann 2000; Frankl and Rubik 2000). The reference literature often suggests large quantitative differences in the use of LC techniques in small and large businesses. There are many reasons for these differences. They include (Kurczewski and Lewandowska 2008):

- Costs of life cycle analyses,

- Costs of changes in routine practices, including investments in technology and fixed assets,

- Complicated methodological tools,

- Shortage of qualified personnel to carry out life cycle analyses.

Studies conducted in the late 1990s by Frankl and Rubik (2000), who analysed the use of LCA-based techniques in four European countries, revealed two issues that are relevant to this publication. Firstly, they proved that the tool was mainly used in the traditional areas of application such as eco-design and environmental labelling, but on the other hand, it was a domain mainly made up of large and very large enterprises, with strong financial, human, research and development resources. Although several years have passed since that publication, it appears that not much has changed in this regard, even though the methodical development of LCA is very intensive. Efforts undertaken by the European Commission to popularize LCA, such as the European LCA Platform (Department of IES, Joint Research Centre (JRC), Ispra) developed in 2005 or the "LCA to go" initiative under the Seventh Framework Programme with an international project scheduled for 2011-2014 "Boosting Life Cycle Assessment Use in European Small and Medium-sized Enterprises: Serving Needs of Innovative Key Sectors with Smart Methods and Tools", prove that implementation of LCA techniques (and other LCT methods) in small- and medium-sized enterprises probably poses a problem.

There are still very few publications in this area, and these show that the costs, acceptable in large enterprises, turn out to be an effective barrier for small- and medium-sized businesses for which the mere awareness of the potential benefits of the implementation of life cycle techniques in their operational practices does not provide a sufficiently strong argument. On the other hand, although the use of LC techniques by small and medium enterprises (SMEs) is still marginal, it is becoming more and more common (Baumann et al. 2012; Schischke et al. 2012; TNO 2005). Among the factors causing a growing interest in the use of analytical tools based on the life cycle concept is the search for:

- Ways to reduce the costs of doing business,

- Innovative solutions with prospects of improving market position,

- The ability to meet legal and ethical requirements, mainly in the area of environmental impact.

In light of the above information, the following questions become significant: What conditions should be met to make LC techniques significantly more widespread? Are small- and medium-sized enterprises ready to accept the life cycle perspective and use it on an everyday basis? Is the specific character of SMEs a source of barriers, or maybe opportunities for LCT? Is it actually possible to implement LCT techniques in the decision-making in SMEs? Or maybe, even if they were willing to do so, it would be rather "LCT formalism" limited to inserting life cycle thinking into the official documents of companies without putting it in the inner workings? The authors of a series devoted to conditions for implementing LC techniques in SMEs in Poland, including, in addition to this article, part 2 (Witczak et al., part 2: LCA-related aspects) and part 3 (Selech et al., part 3: LCC-related aspects), have decided to try to answer these questions. Anticipating financial constraints to be the main potential source of the limited interest of SMEs in LC techniques, they decided to conduct research among those organisations that have received targeted financial support for the implementation of life cycle analyses. This assumption made it possible not only to select a group of companies particularly aware of the benefits of LC 
techniques or characterised by a very good financial potential but also those that actually represent the real-life mediocre situation of SMEs in Poland. On the other hand, however, all respondents who shared their thoughts on the use of LC techniques could provide reliable information based on their own experiences, and not only resulting from the theoretical knowledge of LC techniques.

\section{The specificity of SMEs in Poland}

The research determining the conditions of application of LC techniques by SMEs was conducted on a group of Polish enterprises from across the country. Since small- and medium-sized enterprises constitute a mainstay of the Polish economy, Poland seems to be a good choice for performing this kind of research. It should be stressed that there is a very high proportion of microbusinesses $(95.7 \%)$ in the total number of Polish enterprises (European Commission 2012b). A similar situation also exists in other Central and East European countries like Hungary and Slovenia where the share of microbusinesses is $94.8 \%$ (European Commission 2012a; Bartlett and Bukovic 2001) and $92.8 \%$ (European Commission 2012c; Szita Tóth and Gubik 2005), respectively. In order to give some background to this research, the overall situation of Polish SMEs is presented below, with particular emphasis on their financial capability, environmental activity and prospects for development.

There are about 1.7 million companies in Poland, and their number has been fluctuating in recent years. The vast majority of them-99.8\% - belong to the SME category which also includes microenterprises. The SME sector in Poland is more dominated by microenterprises than the EU average, and the proportion of small businesses involved in the Polish business structure is less than half that of the EU (Polish Agency for Enterprise Development 2012).

According to Eurostat, three quarters of SMEs in Poland carry on business in trade ( 37.7 and $30.6 \%$ in the EU) and services ( 35.4 and $44.3 \%$ in the EU), one in seven-in construction $(15.3 \%, 14.5 \%$ in the EU) and one in ten-in industry (11.6 and $10.6 \%$ in the EU) (Polish Agency for Enterprise Development 2012). Thus, compared to the average for the EU, Poland has many more traders and less service providers.

The small business sector in Poland is significantly smaller than in the EU, measured by its share in the gross value added of businesses. Micro- and, to a lesser extent, medium-sized and large companies make a significantly greater contribution to gross value added in Poland than in the EU-27. SMEs generate every second zloty of GDP (47.6\%), while the smallest of them-nearly one in three zlotys $(29.6 \%)$. The share of medium-sized enterprises is three times lower
$(10.4 \%)$ than that of microenterprises and that of smallsized enterprises is almost four times lower (7.7\%).

The condition of the market in Poland and the EU is determined by SMEs. The number of employees in Polish enterprises amounted to 8.8 million people, of whom 6.2 million $(69.9 \%)$ worked in SME sector entities. The sectors which are the largest employers of labour in Poland are microenterprises run by individuals and large companies created by legal persons. Taken together, they create more than 5.5 million jobs. The number of employees in newly created micro-, small- and medium-sized enterprises amounted to 476.3 thousand people at the end of 2011. Of this number, $64.7 \%$ were employed in enterprises run by individuals (Central Statistical Office 2013).

Nationally, $50 \%$ of capital expenditure is incurred by SMEs and $50 \%$ by large companies. The capital expenditure of service companies at $34.4 \%$ and industrial companies at $31.02 \%$ (as a proportion of the total expenditure of the SME sector) contributes two thirds of SME investments. Two thirds of SME investments are provided from the SME's own funds. In recent years, on average, companies in Poland have reduced the volume of investment in fixed assets to a lesser extent than in other European countries (StarczewskaKrzysztoszek 2011). The overall picture of active enterprises belonging to the SME category is presented in Table 1 and in Fig. 1.

Quality, service and price are among the key factors for the development of enterprises as is generally known from studies described in the literature. The perception of these factors by SME owners in Poland has changed significantly in recent years (Starczewska-Krzysztoszek 2011) (Fig. 2).

Research conducted on behalf of the Polish Agency for Enterprise Development (PAED) (Anuszewska et al. 2011) on a group of over 1,000 Polish SMEs demonstrated that their owners often recognised the important role of environmental impact and the associated opportunity to minimise business

Table 1 Polish SMEs in year 2011—general condition indicators (Szczepaniec 2012)

\begin{tabular}{lc}
\hline Indicator-the percentage of companies & Percentage \\
\hline That had difficulty in finding clients & 34.0 \\
Complaining about excessive market competition & 28.4 \\
Reporting an increase in turnover in the last year & 15.5 \\
Reporting a decrease in turnover in the last year & 30.7 \\
Reporting an increase in profits over the last year & 11.6 \\
Reporting a decrease in profits in the last year & 36.8 \\
That increased employment & 3.0 \\
That reduced employment & 6.2 \\
Reporting an increase of costs in the last year & 44.0 \\
Reporting a decrease in costs in the last year & 4.3 \\
Reporting periodic liquidity problems & 44.9 \\
\hline
\end{tabular}




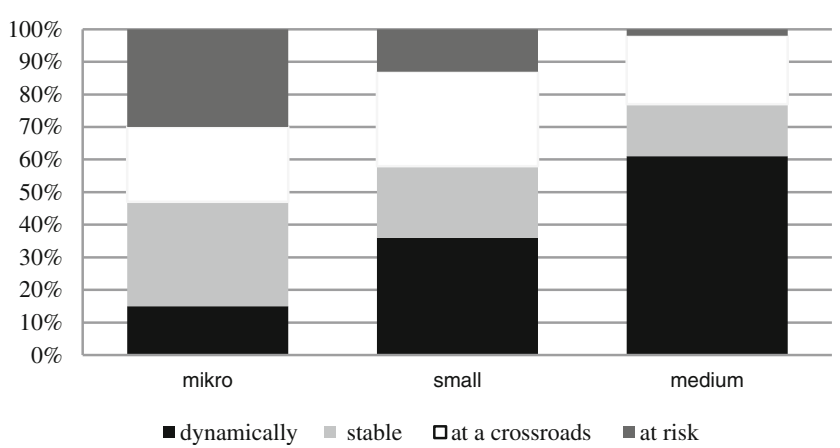

Fig. 1 Polish SMEs in 2011-according to market position and size class

costs among qualitative factors. The most noticeable types of environmental impact of business identified by entrepreneurs are as follows:

- Significant energy consumption (38.5\% of replies),

- Generation of waste requiring disposal (21.8\%) (Anuszewska et al. 2011).

The dominant types of environmental impact exerted by different industries are presented in Table 2.

Of particular note is the fact that despite the awareness of the potential (including financial) benefits of environmental activities, only $5.6 \%$ of the SMEs analysed claimed to have made an environmental audit. Only $39.2 \%$ of them carried out the audit using an objectified measurement system providing knowledge of the actual scale and type of environmental impact (Anuszewska et al. 2011). In most cases, no audit was carried out due to a lack of conviction that a company had an environmental impact. There is thus a correlation between the lack of audit and the lack of awareness of the impact.

Surveys of Polish SMEs indicate that $57.7 \%$ of them took environmental measures in the last 5 years (Fig. 3). Their

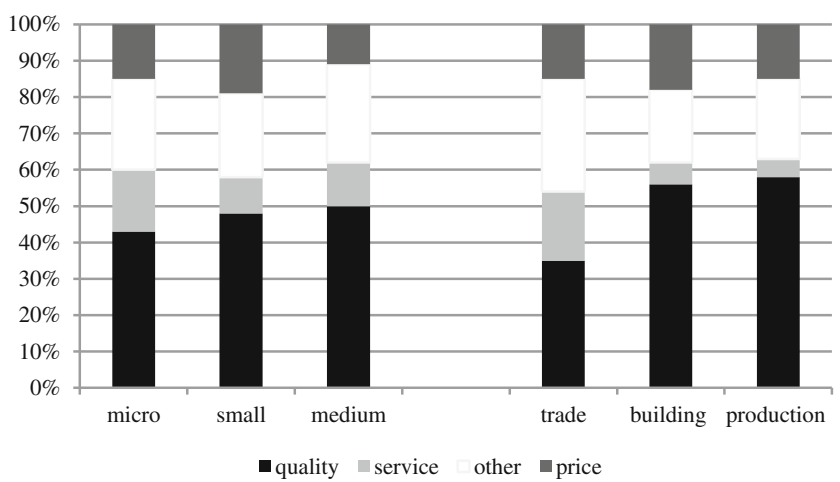

Fig. 2 Polish SMEs in 2011: factors considered crucial for the development of a company's competitive market position - according to size and area of business
Table 2 The types of environmental impact produced by Polish SMEs in 2011 — according to industry (Anuszewska et al. 2011)

\begin{tabular}{|c|c|}
\hline Branch & $\begin{array}{l}\text { Types of environmental impact most noticeable } \\
\text { to managers }\end{array}$ \\
\hline \multirow[t]{2}{*}{ Industry } & Significant energy consumption $(35.2 \%)$ \\
\hline & Generation of waste requiring disposal (31.6 \%) \\
\hline \multirow[t]{4}{*}{ Construction } & Particulate emissions (39.9\%) \\
\hline & Noise $(28.9 \%)$ \\
\hline & Significant energy consumption (29.1\%) \\
\hline & Generation of waste requiring disposal (27.3\%) \\
\hline \multirow[t]{2}{*}{ Trade } & Significant energy consumption (37.9\%) \\
\hline & Generation of waste requiring disposal (25.4\%) \\
\hline \multirow[t]{3}{*}{ Finance } & Significant energy consumption (27.8\%) \\
\hline & Waste requiring disposal (14.2 \%) \\
\hline & Significant water consumption $(13.4 \%)$ \\
\hline \multirow[t]{3}{*}{ Services } & Significant energy consumption (47.5\%) \\
\hline & Generation of waste requiring disposal (14.8\%) \\
\hline & Greenhouse gas emissions (13.2\%) \\
\hline
\end{tabular}

activity in this respect varied according to the size of a company. Medium-sized companies (from 50 to 249 employees) were the most active in this area. In this group, the percentage of companies implementing environmental measures was $76.5 \%$ (Anuszewska et al. 2011).

Research results showing the scale of different types of environmental measures implemented by Polish SMEs are presented in Table 3 (Anuszewska et al. 2011). They indicate that the most commonly implemented measures do not require specialised knowledge or incur large expenditure by companies. Examples include the introduction of energy-efficient light sources or waste segregation practices. More complex projects were undertaken by a very small number of companies, most frequently medium-sized companies with greater financial and human capital.

Eco-design and LCA are for certain among the least common practices of Polish SMEs. This confirms the assertion that LC thinking is still marginal. This is primarily the result of

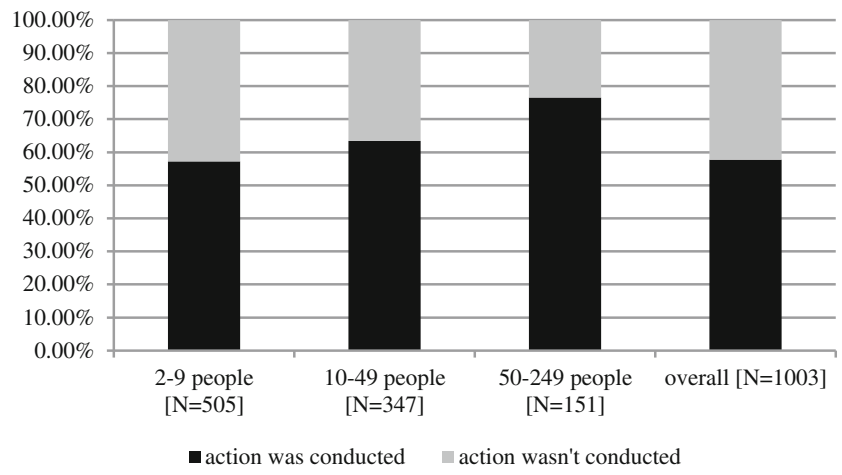

Fig. 3 Pro-environmental action undertaken by Polish SMEs 
Table 3 Scale of environmental measures implemented by Polish SMEs (Anuszewska et al. 2011)

\begin{tabular}{|c|c|c|c|c|}
\hline Type of environmental measures & $\begin{array}{l}2-9 \text { persons } \\
{[N=505]}\end{array}$ & $\begin{array}{l}10-49 \text { persons } \\
{[N=347]}\end{array}$ & $\begin{array}{l}50-249 \text { persons } \\
{[N=151]}\end{array}$ & $\begin{array}{l}\text { Total } \\
{[N=1,003]}\end{array}$ \\
\hline Introduction of energy-efficient lighting & $33.4 \%$ & $39.5 \%$ & $45.1 \%$ & $33.7 \%$ \\
\hline Introduction of waste segregation/recycling practice & $20 \%$ & $26.4 \%$ & $33.4 \%$ & $20.4 \%$ \\
\hline Reduction of waste production & $16.1 \%$ & $20.8 \%$ & $28.3 \%$ & $16.4 \%$ \\
\hline Purchase of new, environmentally friendly equipment/machinery & $15.9 \%$ & $22.3 \%$ & $29.3 \%$ & $16.4 \%$ \\
\hline Training of employees in environmental protection & $12.6 \%$ & $14.7 \%$ & $20.8 \%$ & $12.8 \%$ \\
\hline $\begin{array}{l}\text { Repair of buildings/infrastructure (thermal upgrading), } \\
\text { exchange of heat source }\end{array}$ & $8.4 \%$ & $16.9 \%$ & $19.5 \%$ & $8.9 \%$ \\
\hline $\begin{array}{l}\text { Modernisation of equipment/machinery so that they become } \\
\text { more environmentally friendly }\end{array}$ & $6.9 \%$ & $11.2 \%$ & $19.2 \%$ & $7.3 \%$ \\
\hline Purchase/development of new, environmentally friendly technologies & $5.9 \%$ & $9.6 \%$ & $16.0 \%$ & $6.1 \%$ \\
\hline $\begin{array}{l}\text { Taking organisational measures to reduce the negative } \\
\text { environmental impact of a company }\end{array}$ & $4.1 \%$ & $6 \%$ & $13.1 \%$ & $4.3 \%$ \\
\hline Substitution of more environmentally friendly resources and products & $4 \%$ & $5.2 \%$ & $11.5 \%$ & $4.2 \%$ \\
\hline Conscious use of environmentally friendly products in business practice & $3.8 \%$ & $5.0 \%$ & $10.1 \%$ & $3.9 \%$ \\
\hline Eco-design & $3 \%$ & $2.3 \%$ & $7.8 \%$ & $3.1 \%$ \\
\hline Life cycle assessment of products/services & $2.8 \%$ & $6 \%$ & $8.5 \%$ & $3 \%$ \\
\hline
\end{tabular}

delays in implementing legislation which has already been a standard practice in the EU for years. In particular, this applies to broader product liability or requirements relating to the recording and reduction of pollutant emissions. Hence, there arose the idea to audit whether mechanisms other than just the implementation of legal requirements can effectively induce SMEs to apply LC techniques in practice. In addition, it was decided to identify what can or should be changed in the life cycle analysis tools so that they better produce better expectations among SMEs.

This gave rise to a project involving the free implementation of a number of LCA and LCC processes in Polish SMEs and then the determination of entrepreneurs' opinions about the studies and tools used.

\section{The project investigating the implementation of LCA and LCC in Polish SMEs in practice}

The project involving the implementation of LCA and LCC techniques in SMEs was financed by The Polish Agency for Enterprise Development that supports SMEs and entrepreneurship in Poland in various ways. The project was included in a group of projects conforming to the Innovative Economy Operational Programme, Measure 5.2, and received the title "Development and implementation of pro-innovation optimisation services for SMEs based on an integrated expert system". It was launched in February 2011. All companies classified as SMEs were allowed to participate in it with the exception of a few whose activity was related, for example, to agricultural production. The model of cooperation with each of the SMEs was based on several stages. It assumed:

1. A preliminary assessment of the merits of implementing LCA and/or LCC techniques for a selected company. This evaluation determined whether and how the area of business and its operation satisfy those criteria which had been defined as being necessary in order to implement LCA or LCC. The aim was primarily to ensure that it was possible to obtain the necessary data to carry out the research and to determine the degree of its complexity. It was not possible to exceed a specific budget established for the purpose of implementing LCA and LCC.

2. A company eligible for LCA and/or LCC studies and the selection of a research subject (a product or service offered by the SME); in addition, the research mode was specified (according to a simplified or detailed model).

3. That studies be carried out with the assumption that company personnel would participate in the implementation process.

4. That the results would be discussed with the company's management and would indicate the opportunities for the optimisation of products or services in environmental and economic terms.

Companies not eligible for LCA or/and LCC in the initial stage had the chance to become eligible for the work on the optimisation of the quality of their products or services. The essential part thereof consisted of testing client preferences regarding changes in a company's range of products/services on offer. 
The project assumed that the LCA and LCC results would be used to enable SMEs to:

- Understand the strengths and weaknesses of their products or services in environmental or economic terms,

- Understand possible changes to improve the environmental image and reduce costs over the life cycle of the products or services analysed,

- Generate innovative solutions for the development of their products or services.

\section{Survey}

Almost 100 small- and medium-sized Polish companies participated in the project (described in Section 3) which resulted in implementing almost 100 LCAs or LCCs. It was recognised that this was a proper moment in time to collect all observations and experience gathered during the cooperation with the companies within the project. A survey was performed in order to get information about the companies' opinions and conclusions related to LC techniques. The invitation to take part in the survey was sent to all the companies participating in the project for which LCA and LCC had been carried out. Not all of the 96 companies involved decided to involve themselves in the survey. The invitation was accepted by 25 companies in which LCA had been carried out and 45 companies where an LCC analysis had been made, which gave a group of 70 institutional respondents. It was assumed that all of them would respond to the questions contained in the survey questionnaire, which was divided into four parts. The first three parts of the questionnaire were the same for all types of SMEs, and the content of the fourth part was dependent on the type of analysis carried out in a particular company.

The main objective of the first part of the questionnaire was to obtain general information about a company and its market position. In addition to the basic questions (e.g. name, scope of business), part 1 included questions about:

- The types of management systems used in the company,

- The suppliers of the main resources and products needed to produce a finished product (size, distance from a company and their percentage contribution by volume and value of deliverables),

- A company's position vis-à-vis suppliers of the main resources and products,

- The possibility (degree of difficulty) of replacing suppliers of the main resources and products with others,

- The suppliers of auxiliary resources and products, such as energy carriers, cleaning products, paper and water (their size, distance from a company and their percentage contribution by volume and value of deliverables),
- The position of a company vis-à-vis suppliers of the auxiliary resources and products,

- The possibility (degree of difficulty) of replacing suppliers of the auxiliary resources and products with others,

- The types of clients (their size and distance from a company and their percentage in total sales),

- A company's market share,

- The method of implementation and intensity of activities related to:

- Environmental protection and environmental management,

- Project work and research and development works,

- Quality management,

- Payroll and accounting planning based on employees and products.

Part 2 (Witczak et al., part 2: LCA-related aspects) concerned the identification of causes and the way that LCA and/ or LCC is implemented. Its aims included determining the position of people who agreed to participate in the study and those supervising them. There were also questions aimed at indicating:

- The level of involvement of employees and external experts in the process of data collection,

- Their motives for conducting the analyses (including product planning and development, the provision of a free service, negative opinions about a product, imitating the competition by carrying out similar activities, developing an image in the eyes of clients and suppliers, applying for environmental certifications and labels, collecting materials for the development and implementation of management systems),

- Level of knowledge of the LCA and/or LCC results,

- Top management's knowledge of the study results.

Part 3 (Selech et al., part 3: LCC-related aspects) provided answers on the efficiency of application of life cycle techniques. The issues raised related to:

- An assessment of the usefulness of the LCA and/or LCC results,

- Opinions about the prospective use of the results obtained,

- Objectives for the use of the results (e.g. related to marketing, product and packaging development, building the image of a product and organisation),

- Difficulties in the implementation of LCA and/or LCC analyses,

- The scale and scope of changes in the company as a consequence of the use of the LCA and/or LCC results,

- The prospective use of LCA and/or LCC by the company in the future. 
The content of the final section of the questionnaire was dependent on the type of analysis made for a company (LCA and/or LCC). Its aim was to obtain information on whether and to what extent the organisations analysed undertake activities related to policy development on environmental protection, environmental management and/or costs. Questions posed to the companies that had implemented LCA were to determine:

- Whether the company performed environmental analyses other than LCA (e.g. related to environmental protection, environmental management, eco-friendly activities) and who performed them,

- Whether they evaluated the environmental performance of suppliers and environmental issues in the process of transportation,

- Whether they analysed environmental aspects associated with media and energy consumption,

- Whether they took environmental issues in the design of products and their packaging into account,

- To what extent they were interested in the fate of their products at the end-of-life stage,

- The basis on which the decisions on the shape and development of products were taken prior to the LCA (e.g. imitating competition, analysing client preferences, intuition, searching for market or technical novelties, etc.)

- Criteria that guided their decisions to change the design of their products prior to the LCA (e.g. cost reduction, ensuring competitiveness, compliance with legal requirements, responding to market signals, suggestions of business partners),

- Factors favouring the re-implementation of LCA in the future (e.g. legal requirements, environmental trends, similar measures used by competition, suggestions of suppliers, use of environmental criteria in public procurement, branding requirements).

By answering questions, the companies that had implemented the LCC analyses made it possible to identify:

- What cost analyses were made in them and who carried them out,

- Whether they estimated the costs of after-sales services (e.g. warranty and post-warranty service, maintenance, repairs, etc.) at the stage of development of a new or modification of an existing product,

- Whether they estimated the costs of waste collection and recovery at the stage of a development of a new or modification of an existing product,

- Whether they estimated and analysed the costs incurred by a purchaser through the use of products,

- Whether they determined the costs of disposal (storage) incurred by a purchaser,
- Whether they took the income arising from the sale of recyclables by a buyer into account,

- Environment fees,

- The acquisition costs of materials which were not the final product,

- The costs of environmental prevention and environmental management.

The last two groups of issues were analysed together in those companies where both LCA and LCC analyses had been carried out.

\section{Discussion and conclusions}

This first part of the series of articles on the use of life cycle technologies by Polish SMEs presents the background and assumptions used to study the issue. Comparing Polish SMEs with the same category of companies in the EU, we can observe some similarities, for example, in the percentage of companies engaged in various types of business. There are, however, many more differences. They concern mainly financial parameters, such as the share of this sector in gross value added, or the financial potential which is generally significantly smaller in the case of Polish SMEs than the average in the EU. From the perspective of the research, it is also important that the share of small-sized firms in the SME sector in Poland is less than half that in the EU. The percentage of microenterprises in Poland is much higher.

Assessing the scale of prevalence of LCA and LCC techniques, it must be noted that they are implemented by approximately $3 \%$ of Polish SMEs, as compared to more than $50 \%$ of SMEs taking simple environmental measures (requiring minimal financial investment), so the contribution is very small. Naturally, it is difficult to expect that the use of LC techniques among SMEs will become as frequent as among large companies whose financial potential is many times greater. Against the background of these findings, it seems reasonable to conclude that the vast majority of Polish SMEs do not take measures that do not directly translate into financial benefits or are not imposed on them (e.g. in the form of legal requirements).

The information collected about the specific characteristics of Polish SMEs was used in the development of the survey questionnaire for the companies that had implemented LCA and/or LCC within the project described in Section 3. The form of the questionnaire was also influenced by information collected before (during the preliminary studies on life cycle techniques) and during the implementation of LCAs and/or LCCs. This all helped to formulate a questionnaire, the most important purpose of which was to identify the most significant relationships between data such as: 
- The type of business and its place in the market environment, including cooperating bodies,

- The approach to environmental and economic analyses in the past and their possible applications,

- The approach to the LCA and/or LCC analyses that were implemented and their involvement in learning from them and the implementation thereof,

- The assumed objectives of implementing LCAs and/or LCCs,

- The difficulties identified in the course of the analyses,

- The scale and scope of changes implemented in a company based on the results of the audit, and the changes expected to be implemented in the future.

In accordance with the assumptions, the survey results are intended to identify the key factors determining the use of LC technologies by SMEs. They are presented and discussed in part 2 (Witczak et al., part 2: LCA related aspects) and part 3 (Selech et al., part 3: LCC-related aspects) of the series of articles.

It can be assumed that a significant proportion of those $50 \%$ of Polish companies taking simple environmental measures would be willing to implement life cycle techniques to verify or even increase the effectiveness of the actions taken through these measures. Those who decide about the form and the use of LC techniques still face an open question about what needs to be done to ensure that they are used more frequently by Polish SMEs. The conclusions of the research presented in part 2 (Witczak et al., part 2: LCA-related aspects) and part 3 (Selech et al., part 3: LCC-related aspects) of the series of articles are expected to answer this question.

Open Access This article is distributed under the terms of the Creative Commons Attribution License which permits any use, distribution, and reproduction in any medium, provided the original author(s) and the source are credited.

\section{References}

Agarski B, Kljajin M, Budak I, Tadic B, Vukelic D, Bosak M, Hodolic J (2012) Application of multi-criteria assessment in evaluation of motor vehicles' environmental performances. Tech Gaz 19(2):221-226

Anuszewska I et al. (2011) Sustainable production patterns (SPP) in enterprises activity. Report prepared on behalf of the Polish Agency for Enterprise Development. http://www.parp.gov.pl/files/ 74/75/76/479/12633.pdf. Accessed 29 Dec 2011

Bartlett W, Bukovic V (2001) Barriers to SME growth in Slovenia. MOST: Econ Pol Transit Econ 11(2):177-195

Baumann H (2000) Introduction and organisation of LCA activities in industry. Description and analysis of two LCA projects in Swedish companies. Int J Life Cycle Assess 5(6):363-368

Baumann M, Held M, Herrmann C, Saraev A, Riese O, Steininger H (2012) Ecodesign tool for SMEs in the electronics sector. In: Electronics goes green 2012+. Proceedings of the joint international conference and exhibition, Berlin, Germany, 9-12 September 2012. ISBN 978-3-8396-0439-7, pp 1-8

Bieda B (2012a) Life cycle inventory processes of ArcelorMittal Poland (AMP) S.A. in Kraków, Poland-basic oxygen furnace steel production. Int J Life Cycle Assess 17:463-470

Bieda B (2012b) Life cycle inventory processes of Mittal Steel Poland (MSP) S.A. in Krakow, Poland-blast furnace pig iron production - a case study. Int J Life Cycle Assess 17:787-794

Central Statistical Office (2013) Activity of non-financial enterprises in 2011. Statistical Publishing Establishment, Warsaw

European Commission (2012a) SBA fact sheet Hungary. http://ec.europa. eu/enterprise/policies/sme/facts-figures-analysis/performance-review/ files/countries-sheets/2012/hungary_en.pdf. Accessed 18 Oct 2012

European Commission (2012b) SBA fact sheet Poland. http://ec.europa.eu/ enterprise/policies/sme/facts-figures-analysis/performance-review/ files/countries-sheets/2012/poland en.pdf. Accessed 18 Oct 2012

European Commission (2012c) SBA fact sheet Slovenia. http://ec.europa. eu/enterprise/policies/sme/facts-figures-analysis/performance-review/ files/countries-sheets/2012/slovenia_en.pdf. Accessed 18 Oct 2012

Frankl P, Rubik F (2000) Life cycle assessment in industry and business: adoption patterns, applications and implications. Springer-Verlag, Berlin, Heidelberg

Jensen AA, Remmen A (eds) (2006) Background report for UNEP guide to life cycle management - a bridge to sustainable products

Kurczewski P, Lewandowska A (eds) (2008) The rules of proenvironmental design of technical objects for the management of their life cycle. KMB Printing, Parkowo

Polish Agency for Enterprise Development (2012) Report of the condition of the small and medium enterprises sector in Poland. Publishing Advertising Agency A.Grzegorczyk, Warsaw

Rex E, Bauamnn H (2004) Expanding the green practice in LCA. The first decade of life cycle assessment activity in the Swedish forest products industry CPM-report 2004:1. Chalmers University of Technology, Göteborg, Sweden. CPM - Centre for Environmental Assessment of Product and Material Systems, Göteborg

Schischke K, Nissen NF, Sherry J, O'Rafferty S, O'Connor F, Sitek J, Pamminger R, Wimmer W (2012) Life cycle thinking in small and medium sized enterprises - Status quo and strategic needs in the electronics sector. In: Electronics goes green 2012+. Proceedings of the joint international conference and exhibition, Berlin, Germany, 9-12 September 2012. ISBN 978-3-8396-0439-7, pp 1-6

Schmidt WP, Taylor T (2006) Ford of Europe's product sustainability index. In: Proceedings of 13th CIRP international conference on life cycle engineering, Leuven, Belgium, 31 May-2 June 2006, pp 5-10

Schmidt WP, Dahlqvist E, Finkbeiner M, Krinke S, Lazzari S, Oschmann D, Pichon S, Thiel C (2004) Life cycle assessment of lightweight and end-of-life scenarios for generic compact class passenger vehicles. Int J Life Cycle Assess 9(6):405-416

Starczewska-Krzysztoszek M (2011) Strengths and weaknesses of SMEs. http://konfederacjalewiatan.pl/wydawnictwa/_files/publikacje/ RaportMSP 30 03.pdf. Accessed 7 May 2012

Szczepaniec M (2012) Development of Polish business - an alternative economic program. http://www.koniunktura.com/artykul/open/id/96. Accessed 4 Oct 2012

Szita Tóth K, Gubik A (2005) SMEs in the global transition. In: Managing the process of globalisation in new and upcoming EU members. Proceedings of the 6th international conference of the Faculty of Management Koper, University of Primorska, Congress Centre Bernardin Portorož, Slovenia, 24-26 November 2005. ISBN 961-6573-03-9, pp 205-214

TNO (2005) TNO report. Making life cycle information and interpretative tools available, TNO report B\&O-A R 2005/326. http://ec. europa.eu/environment/ipp/pdf/study_final_clean_report.pdf. Accessed 20 Nov 2008 